\title{
How to make bat's life easier: a new method of chemiluminescent light tags attachment
}

\author{
Olha Timofieieva ${ }^{1,2, *}$, Vitalii Hukov ${ }^{1,3}$, Viktor Kovalov $^{1,2,3}$, Anton Vlaschenko ${ }^{1,3}$
}

\author{
${ }^{1}$ Bat Rehabilitation Center of Feldman \\ Ecopark,Kharkiv Region, Ukraine \\ ${ }^{2}$ Institute of Environmental Sciences, \\ Faculty of Biology, Jagiellonian University, \\ Krakow, Poland \\ ${ }^{3}$ Ukrainian Independent Ecology \\ Institute, Kharkiv, Ukraine \\ *Corresponding author: \\ olgatimofeyeva1997@gmail.com \\ DOI: https://doi.org/10.14709/ \\ BarbJ.12.1.2019.01 \\ Keywords: chiroptera, movement \\ ecology, navigation, risk reduction \\ received: August, 25th 2018 \\ accepted: April, 11st 2019
}

\begin{abstract}
Movement ecology of bats remains insufficiently studied. Chemiluminescent light tags have been a tool for studying this aspect of bat ecology. However, the potential negative impacts of chemiluminescent tags on the health and lifespan of bats has been poorly investigated. In this study, we tested two methods of light tag attachment: 1) standard method, which includes a direct tag application onto animal's fur with glue, and 2) our new proposed method, which uses a cotton wool insert for tag application. Our objectives were to study if bats can remove light tags themselves; study whether there was potential for bats to bite through the plastic casing of the tags (potentially exposing them to risk of intoxication); and to compare the length of attachment of the wool-attachment method against traditional attachment methods. These were tested in two species, namely Nyctalus noctula (6 females, 8 males) and Pipistrellus kuhlii ( 8 females, 6 males). Two light tags (Cormoran, $3 \times 25 \mathrm{~mm}, 0,2 \mathrm{~g}$ ) were attached to each individual (back and stomach). The cotton wool insert was made from a piece of twisted medical cotton wool 20-25 mm long, one side of which was attached to the tag with a glue, and another to the fur. Cotton wool inserts significantly reduced the time required by bats to shed the tag. In both species, light tags without inserts remained attached for 48 hours in $90 \%$ of cases. None of the $N$. noctula individuals without inserts managed to remove light tags either from their stomach or back. We suggest that our new proposed method of light tag attachment allows bats to remove tags faster and therefore reduces possible risks associated with the use of chemiluminescent light tags.
\end{abstract}

\section{INTRODUCTION}

Chemiluminescent tags have been widely used by researchers to study various aspects of bat ecology for over 40 years (Buchler 1976, Becker et al. 2013, Fenton et al. 1998). These light tags when attached to bats with glue can be used to track bat movement during feeding (Encarnação \& Dietz 2006, Encarnação et al. 2010, Andrianaivoarivelo et al. 2011) and migration (Lindecke et al. 2017), in studies of bat microhabitat usage (Christie 2003) and social interactions (Hoxeng et al. 2007), as well as for validation of echolocation calls (Murray et al. 2001). Intraspecific variation in movement can also be studied from hand-released bats. The benefit of chemiluminescent tags is the ability to obtain higher quality recordings because bats are recorded whilst free-flying (in comparison with hand-released bats) and can be followed for a longer time.

Generally, a few hours are usually sufficient to make observations of bats using light tags. However, light tags can remain on experimental animals for up to two days after the end of the study observation period, which may be associated with various hazards. Recently it was shown that the presence of light tags may alter bats' intrasocial behaviour (Hoxeng et al. 2007), with light-tagged individuals being recipients of more aggressive behaviour from other harem members. Moreover, we hypothesize that additional hazards such as chemical intoxication could also be associated with light tags.

Another potential danger, which may arise due to prolonged light tag activity, is the fact that bats may become more visible for predators, such as cats. It was shown recently, that cats are explorative mammals (Machado \& Genaro 2010) and can be easily attracted by various sensory cues. Luminescence from light tags may be one example of such. In addition, cats are opportunistic predators of bats (Woods et al. 2003, Ancillotto et al. 2013). Cats may prey on bats leaving or entering roosts, such as mines or caves (Rodríguez-Durán et al. 2010), as well as hunting bats when they are foraging near the ground (Delpietro et al. 1994).

In September 2017, we tried to use light tags to study the navigation of Nyctalus noctula during their autumn 
migration in the South of Ukraine. For this, we used chemiluminescent light tags (Buchler 1976, Hovorka et al. 1996), with dimensions of $3 \times 25 \mathrm{~mm}$ and weight of $0,18 \mathrm{~g}$. The light tags were attached with glue to the fur on each animal's back and stomach. However, two days after the first bats were released, we re-caught one of the ringed individuals and found the light tags still attached. Over the two days, the animal did not manage to remove the light tags. Moreover, the light tags were still illuminated. We suspended this study because we realized that this approach could be hazardous for animals. Considering the lack of comprehensive studies of the potential negative impact of chemiluminescent tags on bats' health and lifespan (but see Hoxeng et al. 2007 for the risks associated with another type of light tags), we designed a new research project in order to address the following issues: 1) Can bats remove light tags by themselves?; 2) Do bats bite the tags and if so whether they manage to bite through the plastic?; and 3) How can we facilitate self-removal of tags by bats?

\section{MATERIALS AND METHODS}

The study was conducted in the Bat Rehabilitation Centre of Feldman Ecopark, Kharkiv, Ukraine, from February 20 until March 24, 2018. Two species of bats were used: Common Noctule (Nyctalus noctula Schreber, 1774) (six females, eight males) and Kuhl's Pipistrelle (Pipistrellus kuhlii Kuhl, 1817) (eight females, six males), during the bats' winter rehabilitation. These two species were selected because a number of individuals suitable for the experiment was available in the rehabilitation centre.

The experiment included in total 28 individuals: $14 \mathrm{~N}$. noctula and $14 P$. kuhlii. Animals of different sex, and of one age (subadults) were distributed randomly over the replicates. The experiment was performed in a series of 14 replicates, where each replicate consisted of two individuals of the same species exposed to two different attachment types. Only animals with no visible injuries and health disorders were used in this study and each animal was used only once. The weights of $N$. noctula used in the experiment ranged from 24 to $26 \mathrm{~g}$; and of $P$. kuhlii - from 7.5 to $8.0 \mathrm{~g}$.

Two light tags were attached to each animal. We used Cormoran light tags ( $3 \times 25 \mathrm{~mm} ; 0.2 \mathrm{~g})$. These were attached to the animal's fur using surgical glue (Sauer-HAUTKLEBER, type 50.01; Manfred Sauer $\mathrm{GmbH}$ ). The weight of one light tag was less than $1 \%$ from body mass of $N$. noctula and the weight of two light tags was $1.5 \%$; for $P$. kuhlii the weight of one light tag was $2.5 \%$ and of two $-5 \%$. The weight of the wool insert and the glue was less than $0.1 \%$ of bats body mass. One light tag was attached to the stomach in the hypogastric region, the second one to the back (Fig. 1). The tag without wool insert was attached with a very small attachment point, straight to the fur.

In each replicate, one of the animals received both light tags attached directly to the fur, while for the other one a cotton wool insert was used. The cotton wool insert was made from a piece of twisted medical cotton wool 20-25 $\mathrm{mm}$ long. One side of an insert was attached with a glue to a tag, and another one - to the fur (Fig. 2).

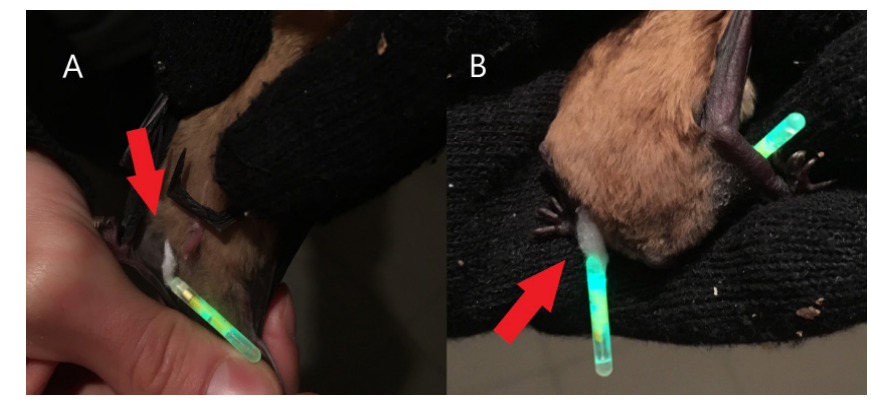

Fig. 1 - Nyctalus noctula with light tags with a cotton wool insert A) on the belly B) on the back.

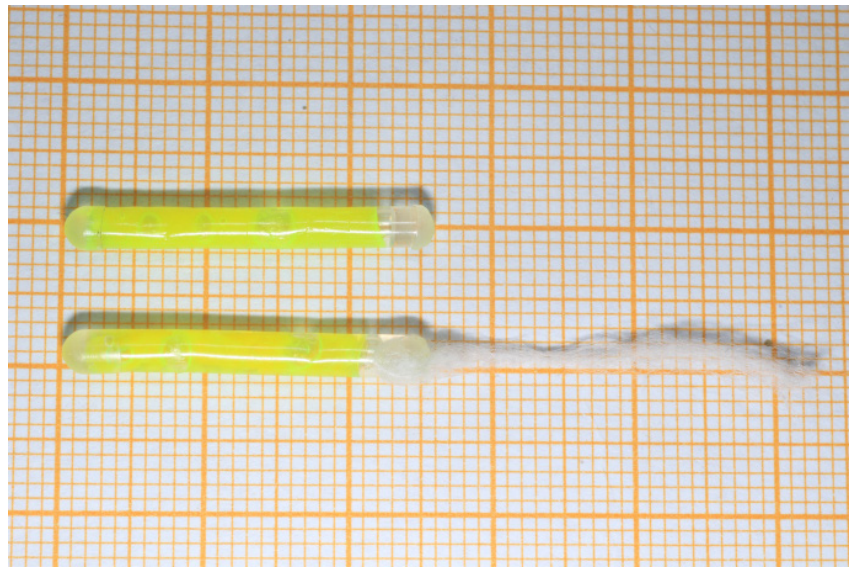

Fig. 2 - Chemiluminescent light tags (Cormoran; $3 \times 25 \mathrm{~mm}$ ) without (on the top) and with (bottom) a cotton wool insert (least square value - $1 \mathrm{~mm}$ ).

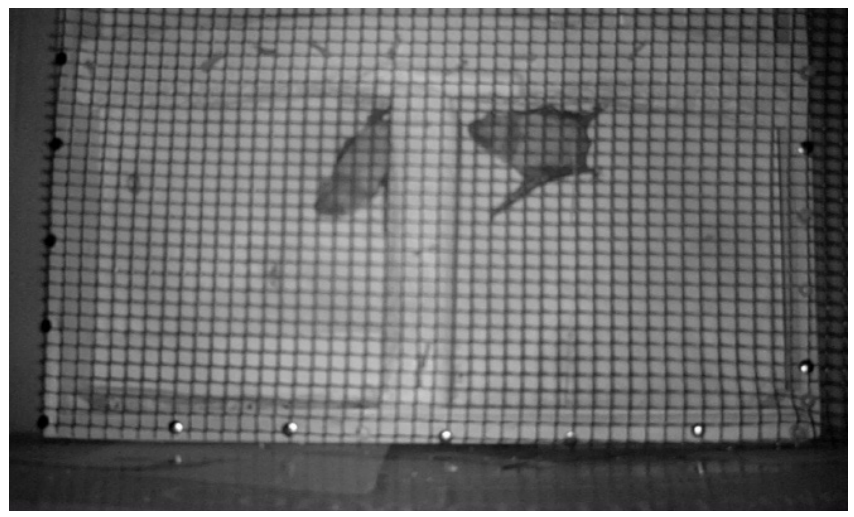

Fig. 3 - Two Nyctalus noctula bats with light tags, each in a separate compartment of a wooden box for bats.

Each individual was placed into a separate compartment of a wooden box designed for bats (500x500x100 mm). The front part of the box $(500 \times 500 \mathrm{~mm})$ was covered with polypropylene net $(12 \times 12 \mathrm{~mm}$ mesh size) (Fig. 3). The animals were left with light tags attached to them for two days (average duration of bright luminescence) at $18-20^{\circ} \mathrm{C}$. This room temperature supported activity of the bats for the duration of the experiment.

Over two days, the bat behaviour including reactions to the light tags was tracked using a camera trap (Browning Dark Ops HD). The camera trap was placed $1 \mathrm{~m}$ from the front of the box and responded to the motion of bats by recording short (15 seconds) videos. We checked videos from the camera trap every 12 hours and we recorded the time passed since the light tag attachment (zero point) to the time of tag removal. After two days, we removed those light tags which bats did not manage to remove by themselves. 
Table 1 - Time taken to remove the light tags; attached with or without a cotton wool insert, for both N. noctula and P. kuhlii. " + ": the animal removed the light tag, "-": the animal did not remove the light tag, n - number of animals.

\begin{tabular}{|c|c|c|c|c|c|c|c|c|}
\hline \multirow{3}{*}{ Animal } & \multicolumn{4}{|c|}{ Nyctalus noctula } & \multicolumn{4}{|c|}{ Pipistrellus kuhlii } \\
\hline & \multicolumn{2}{|c|}{ With insert $(n=7)$} & \multicolumn{2}{|c|}{ Without insert $(n=7)$} & \multicolumn{2}{|c|}{ With insert $(n=7)$} & \multicolumn{2}{|c|}{ Without insert $(n=7)$} \\
\hline & back & stomach & back & stomach & back & stomach & back & stomach \\
\hline 1 & $+12 \mathrm{~h}$ & $+12 \mathrm{~h}$ & $-48 h$ & $-48 h$ & $+5 \min$ & $+5 \min$ & $-48 h$ & $-48 h$ \\
\hline 2 & $+4 \min$ & $+4 \min$ & $-48 h$ & $-48 h$ & $+15 \mathrm{~min}$ & $-48 h$ & $-48 h$ & $-48 h$ \\
\hline 3 & $+40 \min$ & $+56 \min$ & $-48 h$ & $-48 h$ & $+12 h$ & $+12 h$ & $-48 h$ & $-48 h$ \\
\hline 4 & $+2.15 \mathrm{~h}$ & $+12 \mathrm{~h}$ & $-48 h$ & $-48 h$ & $+12 \mathrm{~h}$ & $+12 h$ & $-48 h$ & $-48 h$ \\
\hline 5 & $+12 \mathrm{~h}$ & $-48 h$ & $-48 \mathrm{~h}$ & $-48 h$ & $+12 \mathrm{~h}$ & $+12 \mathrm{~h}$ & $-48 h$ & $-48 h$ \\
\hline 6 & $+12 h$ & $-48 h$ & $-48 h$ & $-48 h$ & $+12 \mathrm{~h}$ & $+12 \mathrm{~h}$ & $+12 h$ & $+12 h$ \\
\hline 7 & $-48 h$ & $+36 h$ & $-48 h$ & $-48 h$ & $+12 \mathrm{~h}$ & $-48 h$ & $+12 \mathrm{~h}$ & $-48 h$ \\
\hline
\end{tabular}

Both these time intervals (in cases of successful, as well as unsuccessful trials) we considered as survival time and used for further statistical analysis. During the experiment, food and water was provided to the animals once a day. In addition, animals' health condition was checked daily. After the experiment concluded, we visually observed light tags (both removed by bats and not removed) for the presence of bites marks.

We used survival analysis to process the obtained data. This analysis is a common statistical method to analyse timeto-event data and make inferences about an influence of different factors on the time to the occurrence of an event of interest (Hosmer et al. 2008). As was mentioned, we analysed survival time - time interval from the experiment start to the moment of tag removal. Cases when individuals did not manage to scrape off light tags were considered as censored data. We tested differences in the survival time between groups, based on the following factors: 1 ) species (N. noctula vs. P. kuhlii), 2) location of the light tag (back vs. stomach) and 3) presence or absence of cotton wool insert. Survival curves were obtained using the Kaplan-Meier estimator of the survival function. Mean survival times in different groups were compared using logrank test.

This research was approved by the Ethics Commission of the V.N. Karazin Kharkiv National University, protocol No. 243.18, 01/02/2018.

\section{RESULTS}

We recorded a total of 7 hours and 13 minutes of video (1253 video records). Analysis of the videos showed that most individuals with light tags affixed without inserts did not remove the tags within 48 hours. Among $N$. noctula animals, none of the individuals $(n=7)$ with light tags without inserts managed to remove them, neither from the stomach or the back. Among P. kuhlii, five out of seven individuals affixed with tags without inserts did not remove the tags. However, one animal removed the tag only from the back and another removed the tags from both fixture points (Table 1).

In contrast, all seven $N$. noctula individuals with tags with inserts removed at least one of them. Two animals managed to remove light tags only from the back, one - only from the stomach, and four animals removed both light tags. In the group of $P$. kuhlii affixed with tags with inserts, 5 out of 7 animals removed both light tags and the remaining two individuals removed tags only from the back.

Statistical analysis showed significant differences in survival times among groups based on the presence or absence of an insert. In both species, tags affixed with inserts were removed over significantly shorter time periods that those affixed without inserts (for $N$. noctule: $\chi 2=17,9, p$ $<0,001$; for P. kuhlii: $\chi 2=11,9, \mathrm{p}=0,0011)$. The place of light tag attachment and the species solely did not affect survival times among groups based on these factors.

Furthermore, light tag remained illuminated throughout the duration of the experiment ( 48 hours). There was no evidence of bats biting the tags, either by video or visual inspection of the tags.

\section{DISCUSSION}

Over recent years researchers working with animals (both in the laboratory and in the field) have been trying to minimize the risks posed to the animals used within scientific studies (Sikes \& Gannon 2011). Thus, when planning experimental studies involving bats, we must ensure that all possible steps have been taken to ensure the animals safety. Many species of bats are threatened; therefore, the development and implementation of methods or tools that minimize stress to these animals are important ethical 
considerations within scientific bat research.

Two decades ago, Hovorka et al. (1996) showed the benefits of plastic shell chemiluminescent light tags over gelatine-capsuled ones. It was shown that plastic shells prevent chemical compounds from leakage which might occur due to softening caused by tag exposure to bat saliva, precipitation or high humidity. In addition, plastic shells are theoretically more resistant to bat biting, although, to the best of our knowledge, there are currently no published studies confirming this assumption. Our results showed that, in the experimental settings used, bats did not bite light tags. Throughout the study period, bats remained in the wooden box and their natural movement was restricted without the ability for free flight. However, we assume that flight may alert the bat to the presence of a light tag; resulting in attempts to bite it off. Bats are social animals and it is probable that other members of the colony may also try to assist in removing the light tags. Taking into account the possibility of puncturing light tags in the natural settings (LaVal et al. 1977), we cannot fully exclude the risk of chemical intoxication followed by subsequent negative effects on animal's health or even death.

Traditionally, a tag without wool insert is attached straight to a bat's fur or skin and the surface of attachment is large. We tried to minimize the attachment surface by attaching tags from the tip (instead of using the whole surface) to the fur (not to the skin) for better removal success. Despite this, in our experiment, $90 \%$ of light tags without inserts remained attached for 48 hours considering both species.

The presence or absence of an insert was the only significant factor affecting the duration of time required to remove the light tag. Considerations concerning the location of light tag attachment therefore need to only consider the potential visibility of a tag during an observation. Furthermore, despite the fact that $N$. noctula are long distance migrants unlike $P$. kuhlii, there was no difference in light tags removal between them. We consider differences within the movement ecology of both species not to affect an animal's behaviour towards light tags.

Chemiluminescent light tags prepared using specific fluid in manufacturing (Hovorka et al. 1996), therefore it is complicated to change its chemical content or physical dimensions. Thus, we modified the method of attachment to animals in order to shorten the time during which the tag remains affixed to a bat and, consequently, to decrease potential risks. Our study showed that a cotton wool insert can be used successfully for this purpose. Alternative materials might also be used for this purpose.

In summary, our new proposed method of light tag attachment allows bats to remove tags faster and therefore reduces possible risks associated with the use of chemiluminescent light tags. Investigations into the navigation and behaviour of bats are very important and necessary. However, since bats are a vulnerable to a number of threats, all possible risks posed to animals during experiments must be considered and mitigated for, even negligible harm. To achieve this goal, new investigative techniques must be developed, or the existing ones must be modified to reduce or eliminate any risks to the health of bats whilst at the same time preserving the effectiveness of the scientific study.

\section{ACKNOWLEDGEMENTS}

The authors are thankful to the International Charitable Foundation "Oleksandr Feldman Foundation" for their support of our bat care activities. The camera trap was supported by the Rufford Foundation (RF) (UK) the project 21319-1 "Key bat hibernacula in North-eastern Ukraine: conservation, population research and monitoring". The research expedition to the South of Ukraine was conducted under the support of EUROBATS Project Initiative, the project "Bats across borders: study of south-eastern bat migration way in Eastern Europe".

We are very grateful to Olena Tkachenko for correction of the English language and to anonymous reviewers for their priceless comments and pieces of advice. We also thank Olena Rodenko, Olena Holovchenko, Dr. Alona Prylutska, Natalia Shaniuk, Margarita Moiseenko, Ilya Nekrutov, Olexandra Kisel for assistance in this study.

\section{REFERENCES}

ANCILLOTTO, L., SERANGELI, M.T. \& RUSSO, D. (2013). Curiosity killed the bat: domestic cats as bat predators. Mammalian Biology, 78(5): 369-373. https://doi. org/10.1016/j.mambio.2013.01.003

ANDRIANAIVOARIVELO, R.A., RAMILIJAONA, O.R., RACEY, P.A., RAZAFINDRAKOTO, N. \& JENKINS, R.K. (2011). Feeding ecology, habitat use and reproduction of Rousettus madagascariensis Grandidier, 1928 (Chiroptera: Pteropodidae) in eastern Madagascar. Mammalia, 75(1):69-78. https://doi.org/10.1515/ mamm.2010.071

BECKER, N.I., TSCHAPKA, M., KALKO, E.K. \& ENCARNAÇÃO, J.A. (2013). Balancing the energy budget in freeranging male Myotis daubentonii bats. Physiological and Biochemical Zoology, 86(3): 361-369. https://doi. org/10.1086/670527

BUCHLER, E.R. (1976). A chemiluminescent tag for tracking bats and other small nocturnal animals. Journal of Mammalogy, 57(1): 173-176. https://doi. org/10.2307/1379522

CHRISTIE, J.E. (2003). Light-tagging observation of microhabitat use and flight behavior by Lesser Shorttailed bats (Mystacina tuberculata). Bat Research News, 44(2): 54-58.

DELPIETRO, H., KONOLSAISEN, F., MARCHEVSKY, N. \& RUSSO, G. (1994). Domestic cat predation on vampire bats (Desmodus rotundus) while foraging on goats, pigs, cows and human beings. Applied Animal Behaviour Science, 39(2): 141-150. https://doi.org/10.1016/01681591(94)90134-1 
ENCARNAÇÃO, J.A. \& DIETZ, M. (2006). Estimation of food intake and ingested energy in Daubenton's bats (Myotis daubentonii) during pregnancy and spermatogenesis. European Journal of Wildlife Research, 52(4): 221-227. https://doi.org/10.1007/s10344-006-0046-2

ENCARNAÇÃO, J.A., BECKER, N.I. \& EKSCHMITT, K. (2010). When do Daubenton's bats (Myotis daubentonii) fly far for dinner?. Canadian Journal of Zoology, 88(12): 11921201. https://doi.org/10.1139/Z10-085

FENTON, M.B., PORTFORS, C.V., RAUTENBACH, I.L., WATERMAN, J.M. (1998). Compromises: sound frequencies used in echolocation by aerial-feeding bats. Canadian Journal of Zoology, 76(6): 1174-1182. https:// doi.org/10.1139/z98-043

HOSMER, D.W., LEMESHOW, S. \& MAY, S. (2008). Applied survival analysis: regression modeling of time-to-event data - 2nd edition. Wiley \& Sons, Hoboken, New Jersey. $416 \mathrm{pp}$.

HOVORKA, M.D., MARKS, C.S. \& MULLER, E. (1996). An improved chemiluminescent tag for bats. Wildlife Society Bulletin, 24(4): 709-712.

HOXENG, C.M., APLING, M.M., RITSON, P.I. \& PORTFORS, C.V. (2007). Light tagging disrupts social dynamics of bat harems. Acta Chiropterologica, 9(1): 161-169. https://doi. org/10.3161/1733-5329(2007)9[161:LTDSDO]2.0.CO;2

LAVAL, R.K., CLAWSON, R.L., LAVAL, M.L. \& CAIRE, W. (1977). Foraging behavior and nocturnal activity patterns of Missouri bats, with emphasis on the endangered species Myotis grisescens and Myotis sodalis. Journal of Mammalogy, 58(4): 592-599. https://doi. org/10.2307/1380007
LINDECKE, O., HOLLAND, R.A., PETERSONS, G. \& VOIGT, C.C. (2017). Beyond the range of echolocation: disentangling essential bat senses for long-distance navigation. 5th International Berlin Bat Meeting, Berlin, Germany. 135pp.

MACHADO, J.C., \& GENARO, G. (2010). Comportamento exploratòrio em gatos domésticos (Felis silvestris catus Linnaeus, 1758): uma revisão. Archives of Veterinary Science, 15(2): 107-117. https://doi.org/10.5380/avs. v15i2.17199

MURRAY, K.L., BRITZKE, E.R. \& ROBBINS, L.W. (2001). Variation in search-phase calls of bats. Journal of Mammalogy, 82(3): $\quad 728-737 . \quad$ https://doi.org/10.1644/15451542(2001)082<0728:VISPCO>2.0.CO;2

RODRÍGUEZ-DURÁN, A., PÉREZ, J., MONTALBÁN, M.A. \& SANDOVAL, J.M. (2010). Predation by freeroaming cats on an insular population of bats. Acta Chiropterologica, 12(2): 359-362. https://doi. org/10.3161/150811010X537945

SIKES, R.S. \& GANNON, W.L. (2011). Guidelines of the American Society of mammalogists for the use of wild mammals in research. Journal of Mammalogy, 92(1): 235-253. https://doi.org/10.1644/10-MAMM-F-355.1

WOODS, M., MCDONALD, R.A. \& HARRIS, S. (2003). Predation of wildlife by domestic cats Felis catus in Great Britain. Mammal review, 33(2): 174-188. https://doi. org/10.1046/j.1365-2907.2003.00017.x 